\title{
Synthesis and electrocatalytic activity towards oxygen reduction reaction of gold-nanostars
}

\author{
G.Oyunbileg $^{1 *}$, G.Batnyagt ${ }^{2}$, B.Enkhsaruul ${ }^{1}$, T.Takeguchi $^{2}$ \\ ${ }^{1}$ School of Arts and Sciences, National University of Mongolia, Ulaanbaatar 210646, Mongolia \\ 2/wate University, 4-3-5 Ueda, Morioka, Iwate 020-8551, Japan \\ *Corresponding author: oyunbileg19@num.edu.mn
}

Received: 29 September 2017; revised: 20 December 2017; accepted: 25 December 2017

\begin{abstract}
The oxygen reduction reaction (ORR) is a characteristic reaction which determines the performance of fuel cells which convert a chemical energy into an electrical energy. Aims of this study are to synthesize Au-based nanostars (AuNSs) and determine their preliminary electro-catalytic activities towards ORR by a rotating-disk electrode method in alkaline electrolyte. The images obtained from a scanning electron microscope (SEM) and a transmission electron microscope (TEM) analyses confirm the formation of the star-shaped nanoparticles. Among the investigated nanostar catalysts, an AuNS5 with smaller size and a few branches showed the higher electrocatalytic activity towards ORR than other catalysts with a bigger size. In addition, the electron numbers transferred for all the catalysts are approximately two. The present study results infer that the size of the Au-based nanostars may influence greatly on their catalytic activity. The present study results show that the further improvement is needed for Au-based nanostar catalysts towards the ORR reaction.
\end{abstract}

Keywords: fuel cell, oxygen reduction reaction, gold nanostars

\section{INTRODUCTION}

The oxygen reduction reaction (ORR) is a characteristic reaction of fuel cell technologies. However, its sluggish kinetics is one of the biggest hurdles for the development of fuel cells for clean energy production [1]. This problem must be solved by a highly active catalyst for the ORR. The state-of-the-art of fuel cell catalysts are based on platinium (Pt) particles [2]. Low abundance, high cost and low stability of $\mathrm{Pt}$ are the most technical limitations in the commercialization of fuel cell technology [3]. To decrease fuel cell cost and to reduce or eliminate the Pt loading, a highly active and cost-effective catalysts are needed in the near future. To enhance the oxygen reduction activity and reduce the amount of $\mathrm{Pt}$ content in electrodes of fuel cells, significant research has been focused on Ptbased alloy catalysts [4-6], non-precious metal catalysts [7-9], metal-free carbon-based catalysts [10-13]. Among these, gold $(\mathrm{Au})$ catalysts have been observed to exhibit moderate activity in alkaline solutions [14-15]. Erikson et al. prepared carbon supported Au catalysts, and observed that their ORR activity varied with the nanoparticle size and the catalyst loading. Zhang et al., Tang et al., and Inasaki et al. investigated the $\mathrm{Au}$ nanoparticle size effects on the ORR activity [16-18]. Their studies reported that the Au nanoparticles with the size ranging from $3 \mathrm{~nm}$ to $10 \mathrm{~nm}$ showed the enhanced ORR activity. Also they reported that the smaller one took a four electron reduction pathway but the larger one took a two electron reduction pathway.

The geometric and electronic structure of nanoparticle catalysts impact greatly on the catalyst performance because the ORR activity largely depends upon the catalyst surface chemistry. Recently, Luna et al. synthesized homogeneous, porous nanostars of a $\mathrm{Pt}$, palladium $(\mathrm{Pd})$ or Pt-Pd alloy shell supported on an Au core and demonstrated their electrocatalytic activity towards the ORR in acidic media. Their catalysts catalyzed the ORR effectively and offered high performance in terms of mass activity and specific activity with high $\mathrm{E}_{1 / 2}$ values of 0.93-0.96 $\vee$ [19].

Au-based nanostars (AuNSs) have been investigated as promising subjects in catalytic, optical and medical research fields because of their specific geometric structure and nature. Few research results on the electrocatalytic activity of the AuNSs towards the ORR have been reported in alkaline condition. In the present study, we aimed to synthesize Pt-free AuNSs and demonstrate their preliminary electrocatalytic activity towards the ORR by a rotating-disk electrode (RDE) technique in alkaline medium.

\section{EXPERIMENTAL}

Materials: Hydrogen tetrachloroaurate (III) trihydrate $\left(\mathrm{HAuCl}_{4} \times 3 \mathrm{H}_{2} \mathrm{O}, 99.999 \%\right.$, Sigma Aldrich), silver nitrate $\left(\mathrm{AgNO}_{3}, 99.99 \%\right.$, Sigma Aldrich), Trisodium citrate dehydrate $\left(\mathrm{C}_{6} \mathrm{H}_{5} \mathrm{O}_{7} \mathrm{Na}_{3} \times 2 \mathrm{H}_{2} \mathrm{O}, 99 \%\right.$, Sigma-Aldrich $)$,

(c) The Author(s). 2017 Open access This article is distributed under the terms of the Creative Commons Attribution 4.0 International License (http://creativecommons.org/licenses/by/4.0/), which permits unrestricted use, distribution, and reproduction in any medium, provided you give appropriate credit to the original author(s) and the source, provide a link to the Creative Commons license, and indicate if changes were made. 
ascorbic acid (AA, $\mathrm{C}_{6} \mathrm{H}_{8} \mathrm{O}_{6}, \geq 99.0 \%$, Sigma Aldrich), and cetyltrimethylammonium bromide (CTAB, $\mathrm{C}_{19} \mathrm{H}_{42} \mathrm{BrN}$, $98 \%$, Sigma-Aldrich) were used to synthesize the nanostars. All reagent stock solutions were prepared with ultrapure deionized water.

Synthesis of gold nanostars (AuNS): A solution containing gold-seed nanoparticles was prepared in the first step. It was prepared by adding $15 \mathrm{ml}$ of $1 \%$ trisodium citrate to $100 \mathrm{ml}$ of a boiling aqueous solution of $1 \mathrm{mM} \mathrm{HAuCl}_{4}$. The resultant solution was boiled for an additional $15 \mathrm{~min}$ and cooled to room temperature in an ice bath. Then the wine-red cold solution was filtered through a $0.22 \mu \mathrm{m}$ nitrocellulose membrane, and stored at $4^{\circ} \mathrm{C}$ until next use. In the second step, AuNSs were synthesized using the as-prepared gold-seed nanoparticles. To obtain the AuNSs, $100 \mu$ of the goldseed solution was added to a $10 \mathrm{ml}$ solution of $0.25 \mathrm{mM}$ $\mathrm{HAuCl}_{4}$ containing $10 \mu \mathrm{l}$ of $1 \mathrm{M} \mathrm{HCl}$, immediately followed by the simultaneous addition of $50 \mu \mathrm{l} 0.1 \mathrm{M} \mathrm{AA}$ and $100 \mu \mathrm{l}$ of $\mathrm{AgNO}_{3}(0.5,2$, or $3 \mathrm{mM}$; samples designated AuNS5, AuNS20 and AuNS30 based upon the $\mathrm{AgNO}_{3}$ concentration) under moderate stirring (700 rpm) for 20 $\min$. Then, AuNS solution was centrifuged at $4000 \mathrm{rcf}$ for $20 \mathrm{~min}$ at $4^{\circ} \mathrm{C}$, the supernatant was discarded, and the particles rinsed with $10 \mathrm{ml}$ of distilled water once. Then it was re-dispersed in $3 \mathrm{ml}$ of distilled water and used for the further investigation.

Catalyst characterization: The morphology and composition of the gold-seed nanoparticles and AuNSs were investigated by the field emission scanning electron microscope (JEOL JSM-7001F) and a transmission electron microscope (JEOL JEM-2100). The electrocatalytic activities of the synthesized nanostars were evaluated using a Solartron $1280 \mathrm{C}$ potentiostat and a rotator (Ametek 636A, Princeton Applied Research) at ambient temperature $\left(25 \pm 2^{\circ} \mathrm{C}\right)$.

Working electrode preparation: The working electrodes supported on glassy-carbon (GC) disk electrodes $\left(0.196 \mathrm{~cm}^{2}\right.$; Pine instrument) were prepared as reported by Suntivich et al. [20]. The GC disk electrodes were polished to a mirror finish with $0.05 \mu \mathrm{m}$ alumina slurry (ALS) before each measurement. Vulcan XC72 carbon was employed as a conducting additive. Nafion (5 wt\%, $0.924 \mathrm{~g} \mathrm{ml}^{-1}$, Sigma-Aldrich) solution was used as a binder of catalysts. For each catalyst, an ink was composed of a mixture of an AuNS solution (200 $\mu \mathrm{l})$, Vulcan XC72 (5 mg), and the 5\% Nafion solution $(20 \mu \mathrm{l})$ dispersed in a mixture of $3 \mathrm{ml}$ water and $2 \mathrm{ml}$ ethanol. The ink was sonicated in an ice bath for $1 \mathrm{~h}$ in order to obtain a homogenous ink. Then, $10 \mu \mathrm{l}$ of the ink was drop-cast onto a GC disk electrode and dried in a static air for at least $30 \mathrm{~min}$.

Electrochemical measurements: RDE measurements were carried out in a three-electrode Teflon cell. A 0.1 $\mathrm{M} \mathrm{KOH}$ electrolyte $(100 \mathrm{ml})$ was freshly prepared from Milli-Q water $(18 \mathrm{M} \Omega \mathrm{cm}$ ) and $\mathrm{KOH}$ (99.99\%, SigmaAldrich) before each measurement. A platinum spiral and $\mathrm{a} \mathrm{Hg} / \mathrm{HgO}$ electrode were used as counter (CE) and reference (RE) electrodes, respectively. The RE was calibrated in the same electrolyte by performing hydrogen oxidation/evolution currents on a $\mathrm{Pt}$ plate using the RDE. The potential of zero current was determined as the reversible hydrogen electrode (RHE) potential and $0 \mathrm{~V}$ vs. RHE corresponds to $0.85 \mathrm{~V}$ vs. $\mathrm{RE}$ in this study. All the potentials were referenced to the RHE potential scale, and iR-corrected if necessary. The uncompensated ohmic electrolyte resistance $(\approx 40 \Omega$ ) was determined via the impedance experiment in the same electrolyte. The electrolyte was degassed with $\mathrm{N}_{2}$ gas before the electrochemical measurements. The ORR activities were measured by hydrodynamic voltammetry using a $\mathrm{RDE}$ in an $\mathrm{O}_{2}$-saturated $0.1 \mathrm{M} \mathrm{KOH}$ at room temperature between $0.3 \mathrm{~V}$ to $1.1 \mathrm{~V}$ vs. RHE at a scan rate of $10 \mathrm{mV} \mathrm{s}^{-1}$ with different rotation speeds. The capacitive current of AuNSs catalysts was removed by subtracting the ORR polarization trace of $\mathrm{O}_{2}$ from linear sweep voltammograms in $\mathrm{N}_{2}$ at the same scan rate.

\section{RESULTS AND DISCUSSION}

The syntheses of AuNSs were initiated the preparation of gold-seed nanoparticles. Using the gold-seed nanoparticles, three types of AuNSs were synthesized by a seed-mediated method according to the report of Andrew et al. [21]. AuNSs are designated by the final concentration of $\mathrm{AgNO}_{3}$ which is used to control the branching. For examples, AuNS5, AuNS20 and AuNS30 were obtained using $5 \mu \mathrm{M}, 20 \mu \mathrm{M}$ and $30 \mu \mathrm{M}$ of $\mathrm{AgNO}_{3}$ solution, which was added to the reaction mixture. In the synthesis of AuNSs, AA serves as the reducing agent, with silver nitrate used as the precursor to elemental silver.

The formation of the gold-seed nanoparticles was confirmed by its TEM images shown in Figure 2. The gold-seed nanoparticles are homogeneous and have an average particle size around $12-16 \mathrm{~nm}$ which was consistent with the size reported by Andrew et.al. In addition, the SEM (Figure 1) and TEM (Figure 2) images were used to confirm the formation of AuNSs. The SEM and TEM images of all the samples clearly show starlike shapes. In SEM images, the star-like shapes were clearly observed for all the catalysts.

From the TEM images, among the three types of AuNSs, they vary in core size of the particle, the length, and number of branches. With AuNS5 having a smaller core and few broad branches, the amount of silver required for subtotal coverage is less than that from AuNS30, having a larger core and more sharp branches. The ORR activities of as prepared AuNSs catalysts were carried out in oxygen-saturated $0.1 \mathrm{M} \mathrm{KOH}$ solution on a glassy carbon electrode at room temperature. Figure 3(a) compares the ORR activities of AuNS5, AuNS20, AuNS30 at a rotating rate of $1600 \mathrm{rpm}$. AuNS5 showed $25 \mathrm{mV}$ more positive potential compared with AuNS20 and AuNS30 catalysts, indicating an enhanced ORR activity of AuNS5. The better behavior of AuNS5 may be attributed to a smaller core size of AuNS5 catalysts. $\mathrm{Pt} / \mathrm{C}$ still shows the highest activity (Figure 3(b)). In the Figure 3(a) and 3(b), the linear sweep voltammograms in the negative-going direction were normalized to the geometric surface area of the working electrode. 

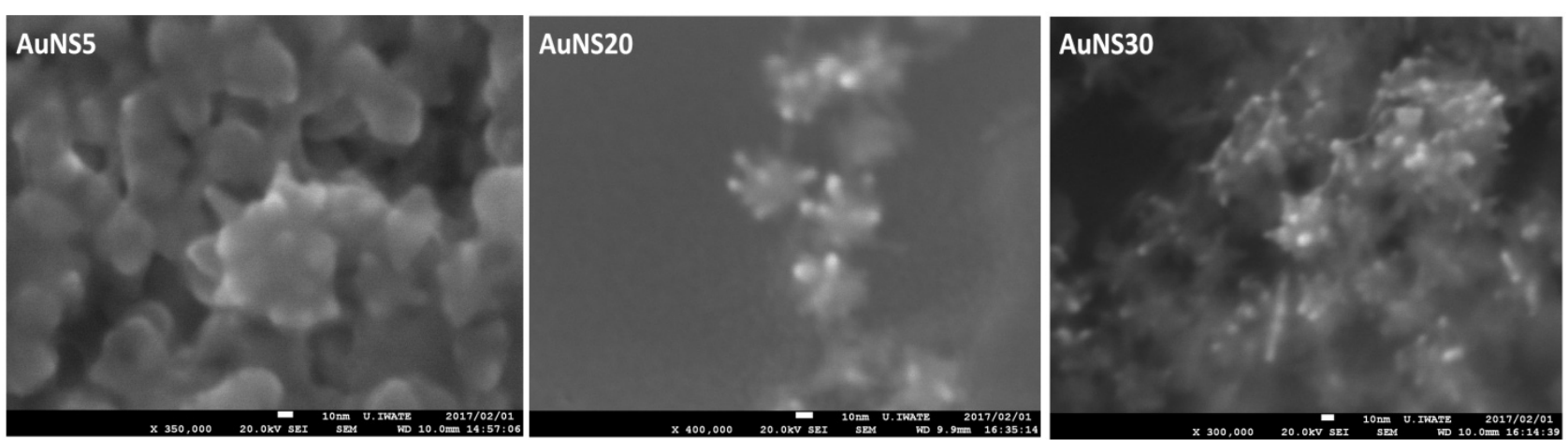

Fig. 1. SEM images of the AuNS5, AuNS20 and AuNS5 nanostars. A bar equals to $10 \mathrm{~nm}$.
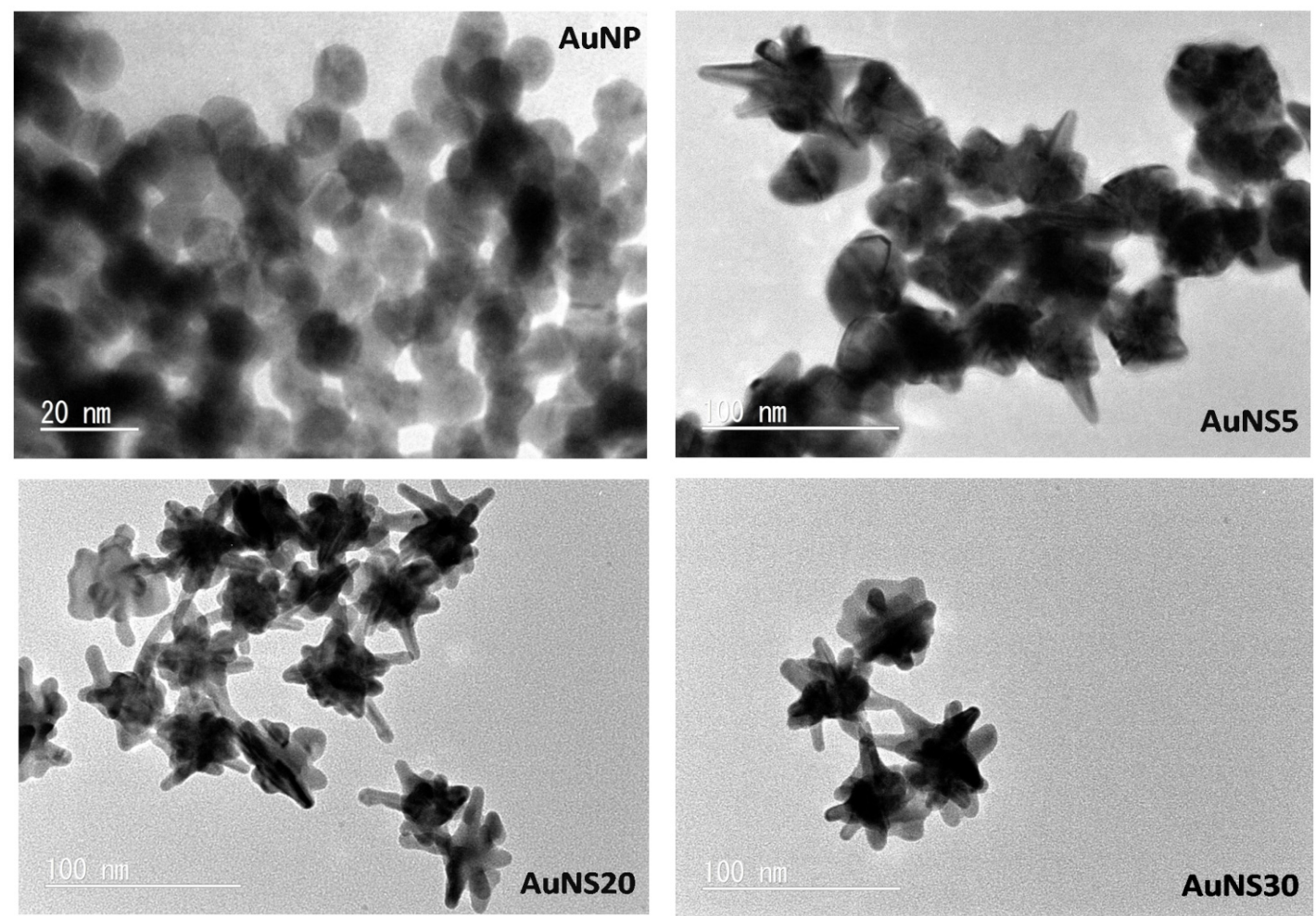

Fig. 2. TEM images of the AuNS5, AuNS20 and AuNS5 nanostars.

A bar equals to $20 \mathrm{~nm}$ for Au-seed nanoparticles and $100 \mathrm{~nm}$ for nanostars.
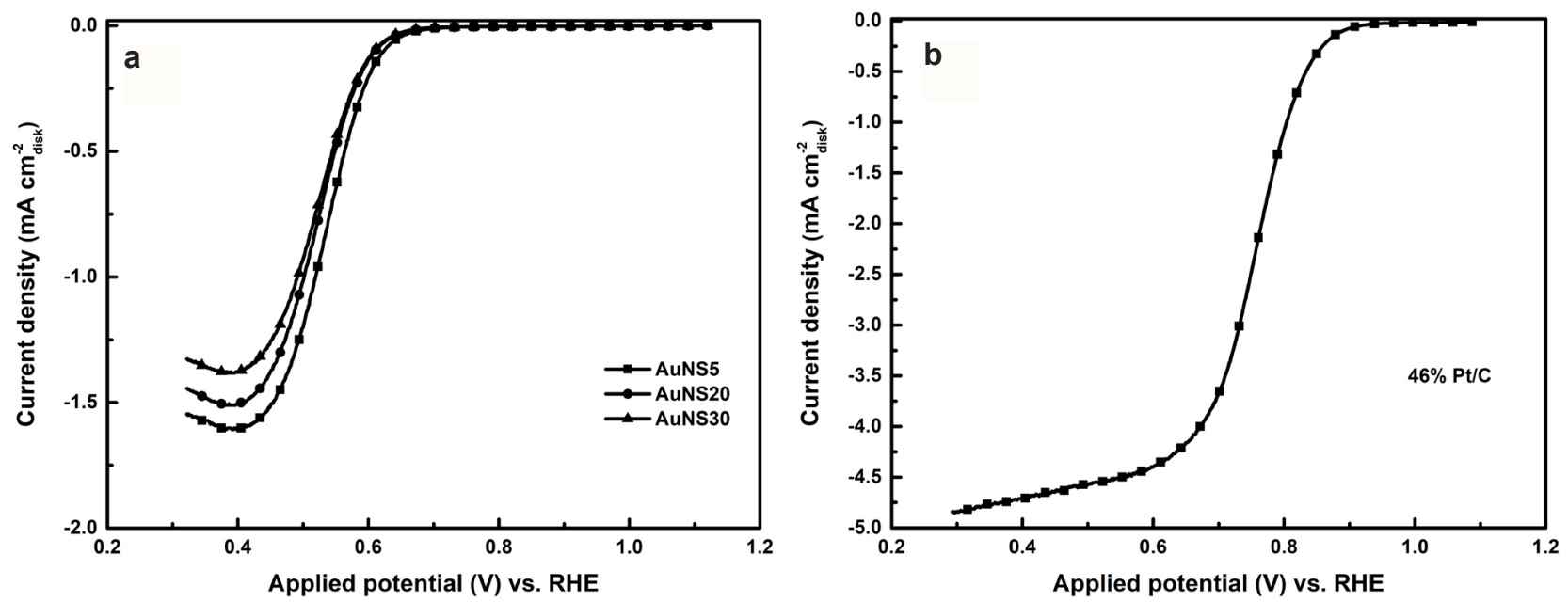

Fig. 3. A. The ORR activities of AuNS5, AuNS20, AuNS30, and B. the ORR activity of $\mathrm{Pt} / \mathrm{C}$ catalysts in $\mathrm{O}_{2}$-saturated $0.1 \mathrm{M} \mathrm{KOH}$ at $1600 \mathrm{rpm}$. 
Among the investigated catalysts, AuNS5 exhibited the highest limiting current density $\left(1.6 \mathrm{~mA} \mathrm{~cm}{ }^{-2}\right)$ and the largest onset reduction potential $(0.65 \mathrm{~V})$ for the ORR. As shown in Figure 3(a), the electrocatalytic activities of the AuNSs increased in the order of AuNS30 < AuNS20 < AuNS5. With increasing the Ag amound in the AuNSs, the increase in the length and number of branches of nanostars was observed in the TEM images as well as SEM images. However, the electrochemical measurements indicated that the catalytic activity of AuNSs towards ORR was not influenced by the number and length of branches in AuNSs catalysts. It may suggest that core size of the nanostars plays in important role in their catalytic activity. To evaluate the kinetics of ORR of as prepared AuNSs catalysts, the reaction kinetics were evaluated by the RDE method. The steady-state polarization curves were recorded from 0.3 to $1.1 \mathrm{~V}$ vs. $\mathrm{RHE}$ at a scan rate of $10 \mathrm{mV} \mathrm{s}^{-1}$ in $\mathrm{O}_{2}$-saturated $0.1 \mathrm{M}$ $\mathrm{KOH}$ by varying the rotation rates.
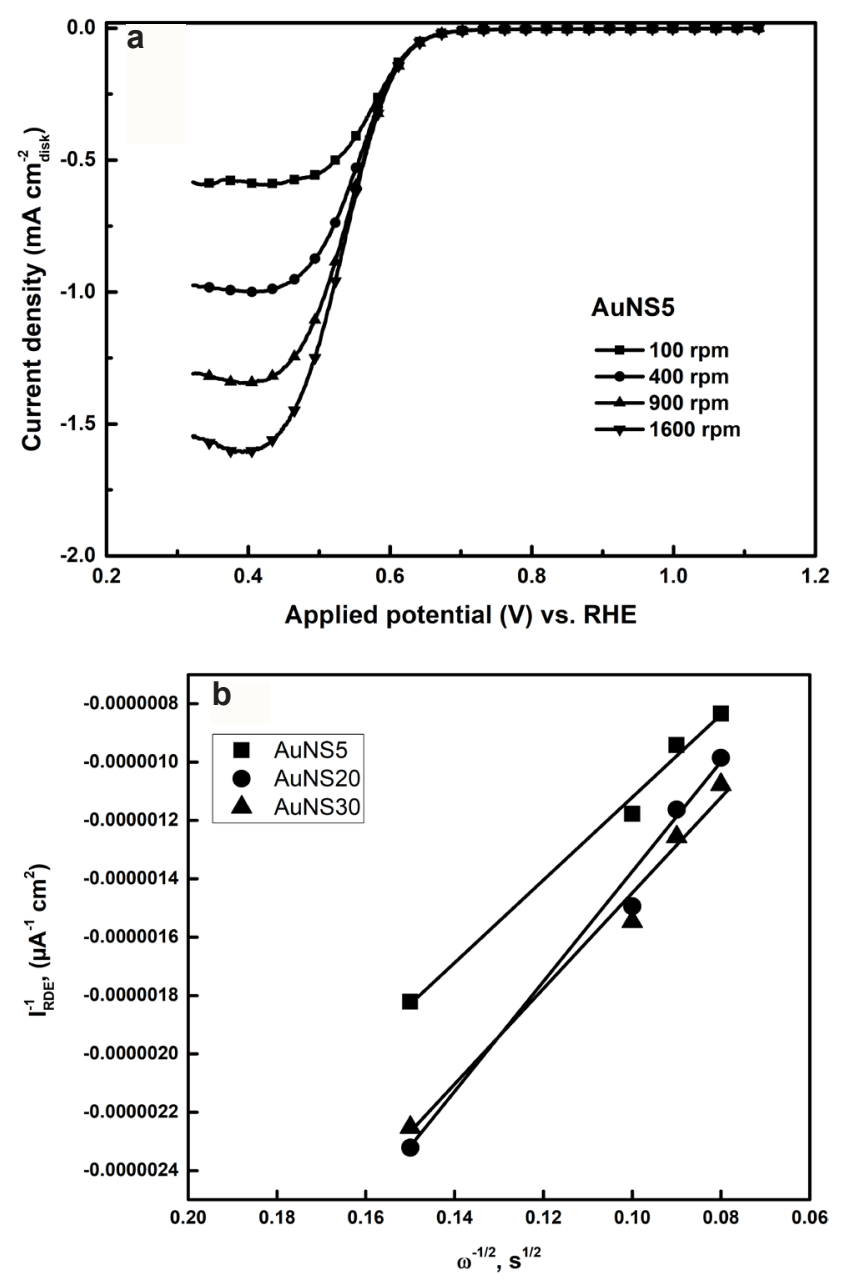

Fig. 4(a). The ORR activities of AuNS5 at $100,400,900$, and $1600 \mathrm{rpm}$.

(b) Kottecky-Levich plots of AuNS5,

AuNS20 and AuNS30 at $0.5 \mathrm{~V}$ vs. RHE.

Figure 4(a) shows the rotating-disk voltammograms of oxygen reduction recorded at AuNS5 electrode in an $\mathrm{O}_{2}$-saturated $0.1 \mathrm{M} \mathrm{KOH}$ solution at different rotation rates. Figure 4(b) depicts the Kottecky-Levich (K-L) plots with good linearity of AuNS5, AuNS20, and AuNS30 catalysts. The kinetic parameters can be analyzed with the Koutecky-Levich equation (Equation 1).

$$
\frac{1}{j}=\frac{1}{j_{k}}+\frac{1}{j_{d}}=\frac{1}{n F A k C_{O_{2}}}+\frac{1}{0.62 n F A D_{O_{2}}^{2 / 3} v^{-1 / 6} C_{O_{2}} \omega^{1 / 2}}
$$

\section{Where:}

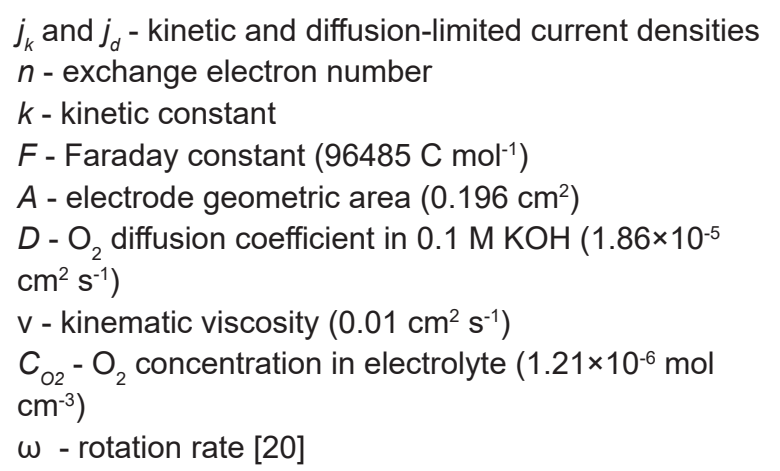

According to this equation, the number of electrons transferred $(n)$ and $j_{k}$ can be obtained from the slope and intercept of the K-L plots, respectively. To obtain the number of electrons transferred in the ORR and kinetic current density $\left(j_{k}\right)$, the overall current density was plotted against the square root of the angular velocity ( $\omega^{-}$ $\left.{ }^{1 / 2}\right)$. The electron number of transferred in the ORR for all the AuNSs is found to be about two. The results indicate that the further improvement is needed to increase the ORR activity of these catalysts.

\section{CONCLUSIONS}

We have demonstrated preliminary electrocatalytic activities of Au-based nanostars towards the ORR reaction. Among the investigated nanostar catalysts, a AuNS5 with smaller size and a few branches showed the highest electrocatalytic activity. It infers that the size of the Au-based nanostars may influence greatly on their catalytic activity. In addition, the present study results show that the further improvement is needed for this kind of catalysts and subject to next study.

\section{ACKNOWLEDGEMENTS}

Financial support from Mongolia-Japan Engineering Education Development (MJEED-JR13B15) and Asian Research Center (P2016-1281) are gratefully acknowledged.

\section{REFERENCES}

1. Viswanathan B., and Scibioh M.A. (2007) Fuel cells: Principles and Applications, CRC Press, Boca Raton, FL.

2. Gasteiger H.A., Kocha S.S., Sompalli B., and Wagner F.T. (2005) Activity benchmarks and requirements for $\mathrm{Pt}$, Pt-alloy, and non-Pt oxygen reduction catalysts for PEM-FCs, Applied Catalysis B: Environmental, 56, 9.

3. Debe M.K. (2012) Electrocatalyst approaches and challenges for automotive fuel cells, Nature, 486, 43.

4. Zhou Y., Neyerlin K., Olson T.S., Pylypenko S. et 
al. (2010) Enhancement of Pt and Pt-alloy fuel cell catalyst activity and durability via nitrogen-modified carbon supports. Energy Environmental Science, 3, 1437.

5. Perez H., Morin A., Akrour L., Cremona C. et al. (2010) Evidence for high performances of low Pt loading electrodes based on capped platinum electrocatalyst and carbon nanotubes in fuel cell devices. Electrochimica Acta, 55, 2358.

6. Wang C., Chi M., Li D., Strmcnik D. et al. (2011) Design and synthesis of bimetallic electrocatalyst with multi-layered Pt-skin surfaces. Journal of American Chemical Society, 133, 14396.

7. Wu G., More K.L., Johnston C.M., and Zelenay P. (2011) High-performance electrocatalysts for oxygen reduction derived from polyaniline, Iron, and Cobalt, Science, 332, 443.

8. Chen Z., Higgins D., Yu A., Zhang L. et al. (2011) A Review on non-precious metal electrocatalysts for PEM fuel cells. Energy \& Environmental Science, 4, 3167.

9. Bezerra C.W.B., Zhang L., Lee K., Liu H. et al. (2008) A Review of Fe-N/C and Co-N/C catalysts for the oxygen reduction reaction. Electrochimica Acta, 53, 4937

10. Sun C.L., Chen L.C., Su M.C., Hong L.S. et al. (2005) Ultrafine platinum nanoparticles uniformly dispersed on arrayed cnx nanotubes with high electrochemical activity. Chemistry Materials, 17, 3749.

11. Wang C., Waje M., Wang X., Tang J.M. et al. (2004) Proton exchange membrane fuel cells with carbon nanotube based electrodes. Nano Letters, 4, 345.

12. Bessel C.A., Laubernds K., Rodriguez N.M., Baker R.T.K. (2001) Graphite nanofibers as an electrode for fuel cell applications. Journal of Physical Chemistry $B, 105,1115$.

13. Cao J., Chen Z., Xu J., Wang W. et al. (2013) Mesoporous carbon synthesized from dual colloidal silica/block copolymer template approach as the support of platinum nanoparticles for direct methanol fuel cells. Electrochimica Acta, 88, 184.
14. Erikson H., Sarapuu A., Tammeveski K., Solla-Gullòn J. et al. (2014) Shape-dependent electrocatalysis: oxygen reduction on carbon-supported gold nanoparticles. Chem. Electro. Chem., 1, 1338-1347.

15. Yin H., Tang H., Wang D., Gao Y. et al. (2012) Facile synthesis of surfactant-free au cluster/graphene hybrids for high-performance oxygen reduction reaction. ACS Nano, 6, 8288-8297.

16. Zhang G.R., Xu B.Q. (2013) Nano-size effect of Au catalyst for electrochemical reduction of oxygen in alkaline electrolyte. Chin. J. Catal., 34, 942-948.

17. Tang W., Lin H., Kleiman-ShwarscteinA., Stucky G.D., McFarland E.W. (2008) Size-dependent activity gold nanoparticles for oxygen electroreduction in alkaline electrolyte. J. Phys. Chem. C, 112, 10515-10519.

18. Inasaki T., Kobayashi S. (2009) Particle size effects of gold on the kinetics of the oxygen reduction at chemically prepared au/c catalysts. Electrochem. Acta, 54, 4893-4897.

19. Luna B.V., Jefferson B., and Gilberto M. (2016) Superior catalysts for oxygen reduction reaction based on porous nanostars of a $\mathrm{Pt}, \mathrm{Pd}$, or Pt-Pd alloy shell supported on a gold core. Chem. Electro. Chem., 3, 749-756.

20. Suntivich J., Gasteiger H.A., Yabuuchi N., and Shao-Horn Y. (2010) Electrocatalytic measurement methodology of oxide catalysts using a thin-film rotating disk electrode. J. Electrochem. Soc., 157, B1263-1268.

21. Andrew M.F., Hsiangkuo Y., and Tuan V-D. (2014) Development of hybrid silver-coated gold nanostars for non-aggregated surface-enhanced raman scattering. J. Phys. Chem. C, 118, 3708-3715. 